\title{
The Role of Professional Organizations in Boosting Trust in Financial Business
}

\author{
Brian K. Atchinson ${ }^{\mathrm{a}}$ \\ aMSA, Two Wisconsin Avenue, Ste 320, Chevy Chase, MD 20815, USA. \\ E-mail: brianatchinson@imsaethics.org
}

In today's challenging business climate, a variety of constitutencies in the financial services industry are looking to professional standard setting organizations to establish and promote Best Practices in the marketplace. Such organizations, working with financial services companies and regulators, can accomplish a great deal to promote consumer trust. In addition, there are encouraging indications that the value of professional organizations is being recognized and, therefore, woven into the future regulatory and marketplace infrastructure.

The Geneva Papers (2005) 30, 477-484. doi:10.1057/palgrave.gpp.2510041

Keywords: best practices; ethics; self-regulatory organizations; trust

\section{Introduction}

The financial services industry in much of the world has much to be proud of - a recent history of innovation in product design makes it possible for many people to take personal responsibility for their future financial well-being. This success is helping to fuel economic growth in many countries, notwithstanding the different regulatory philosophies and structures among the different countries. The recent work and accomplishments of the International Association of Insurance Supervisors (IAIS) has demonstrated that, while transparent and consistent regulation is vital, there is no single correct supervisory approach for successfully bringing about a healthy insurance marketplace. Transparency breeds confidence and trust among consumers and investors.

Recently, the financial services industry in the United States has suffered significant damage to its reputation as a result of investigations and enforcement actions by government regulators and lawsuits filed by aggrieved consumers. It is an issue, a story, that will be told over time. In a 2005 speech at the National Press Club in Washington, DC, New York Attorney General Eliot Spitzer said, "The insurance industry has corruption that is rife throughout it, rife. It touches every line of insurance that is purchased, every line. And we will keep going until we find it."1

U.S. companies operating in the environment following revelations of wrongdoing real and alleged - are increasingly facing new challenges on two key fronts. First, there is an intensified level of regulatory scrutiny that could have a significant impact on the way insurance products are sold. Second, repeated media references to financial

\footnotetext{
${ }^{1}$ National Press Club Newsmakers Luncheon (2005).
} 
services companies in conjunction with terms such as "scandal" and "abuse" have created cause for concern among consumers.

Continuing focus by both state and federal regulators and new stories in the media will create not just reputation risk issues for companies but also may result in financial consequences. Establishing and communicating trust has quickly evolved from simply a good message for companies to promote into a key component of a company's financial and business plan intended to create bottom-line success.

The management of different companies reacts to different stimuli. Decisions can be driven by investor expectations, consumer needs or marketplace opportunities while others are intended to address regulatory or legal imperatives.

\section{The value of professional organizations}

In this environment, it is not surprising that professional standard setting organizations are finding strong interest among the many different constituencies that seek some degree of consistency, predictability or reliability. There are a number of these organizations operating in the financial services sphere. They take many shapes and attain varying levels of credibility. They are sometimes referred to as Professional Organizations, Best Practices Organizations, Self-regulatory Organizations or other nomenclature. One common thread runs throughout these organizations: Each has as a part of its mission the enforcement of certain "standards" that are designed to enhance quality and to foster consumer, industry, investor or regulatory trust in the marketplace. The creation of standards against which companies can be measured or distinguish themselves can be a considerable trust-building factor. Companies that go through a special accreditation or assessment or licensing process can point to that qualification with purchasers, regulators and the media.

The concept of a "culture of compliance" is gaining considerable attention in the financial services arena, from corporate boardrooms to regulatory agencies. As a result of well-publicized problems in numerous financial services companies, government officials and industry leaders are seeking solutions and crafting messages to reassure the public.

It is in this context that some leaders, including John Walsh, the Chief of the U.S. Securities and Exchange Commission's Office of Inspections and Examinations, have set forth 10 elements of a "culture of compliance."

The elements of a company with a well-developed "culture of compliance" will include

- A clear and decisive leadership tone of ethical behavior at the top of the organization.

- Thorough training of company employees and all those acting on its behalf.

- Empowerment and encouragement of employees to identify and even challenge questionable conduct.

- Integration of compliance and risk assessments into business decision-making.

- Continuous organizational self-assessment.

- Regularly updated policies and procedures for operational monitoring and feedback. 
- Consistent allocation of adequate financial resources for compliance functions.

- Detection of a problem is dealt with quickly and appropriately.

- Senior management and the Board of Directors are kept well-informed on a regular basis.

- Government regulators are informed of violations identified through self-audits and assessments.

This final element, the self-reporting of problems, can be a particularly challenging component of a culture of compliance. When and how to self-report problems once identified is a complex determination. Taking the initiative by informing regulators of a problem before it is discovered is difficult for some organizations to do. But there have been numerous instances in recent years in the United States where companies have done so and benefited - from regulatory, media and consumer perspectives.

As the NASD's President of Regulatory Policy and Oversight Mary Schapiro said, "self-reporting is not a get-out-of-jail free card.", But firms that self-report gain credibility with regulators for the specific problem and in general. In addition, NASD confirms that self-reporting firms face lower settlement sanctions than they would otherwise and, when issuing public information on the matter, NASD notes prominently that the company brought the matter to their attention. This can have a positive impact with the media and with consumers.

\section{Professional organizations - U.S. examples}

In the United States, these professional organizations have typically been developed to address specific subject or functional areas in the financial services field. For example, in the health and medical insurance context, these organizations often fill voids not otherwise addressed by existing regulatory or industry functions. A short review of the dominant professional organizations in this field will provide some perspective on the opportunities and challenges for such organizations and those who rely upon them.

\section{Health and medical insurance}

$U R A C$

URAC is an independent, nonprofit organization committed to promoting health care quality through accreditation, certification and other quality improvement activities. ${ }^{3}$ It has filled a void to provide quality assurance reviews for various functions typically found in health delivery plans and related insurance programs. URAC has a diverse group of members and supporters that include the United Auto Workers, the National Association of Manufacturers, the American Medical Association and the National Association of Insurance Commissioners.

URAC offers about 20 accreditation programs, including standards for health maintenance organizations and preferred provider organizations, workers' compensation organizations and functions, case management, disease management and health

\footnotetext{
${ }^{2}$ Remarks by Mary L. Schapiro (2005).

${ }^{3}$ URAC (2005).
} 
web site accreditation. Regulators are able to access much of the information that URAC reviews in its organizational reviews, a fact that companies understand prior to undergoing the URAC accreditation process. The standards of URAC are developed through an open process that involves representatives of all the stakeholders interested in the U.S. healthcare system. There is also a public comment period on proposed standards. ${ }^{4}$ URAC accreditation is relied upon and recognized by the majority of states and the Federal government for quality assurance for health-plan functions.

\section{National Committee on Quality Assurance (NCQA)}

The NCQA is a private, not-for-profit organization that also focuses on the quality of healthcare in the U.S. Established in 1991, NCQA evaluates health plans in three ways: through facility accreditation based on formal inspections and reviews, through Health Plan Employer Data and Information Set (HEDIS) that measures health plan performance in a number of key treatment and outcome areas such as mammography screening and immunization, and through a comprehensive membership survey. ${ }^{5}$

In addition to longstanding relationships with employers and consumer groups, NCQA has created collaborative partnerships with many state regulators and the U.S. federal government to "streamline regulatory oversight and improve quality review."

\section{Professional organizations - financial services}

In other areas of the financial services marketplace, there have been different types of success with Professional Organizations, ranging from a federally chartered selfregulatory organization (SRO) to an independent standard-setting organization promoting ethical business practices.

\section{National Association of Securities Dealers (NASD)}

The NASD is the primary private-sector regulator of the U.S. securities industry. It licenses individuals and admits firms to the industry, writes rules to govern their behavior, examines them for regulatory compliance and disciplines those who fail to comply. In addition, the NASD oversees and regulates trading in equities, corporate bonds, securities futures and options. ${ }^{6}$

The NASD system has been used "as a tool to create uniformity between the state securities regulators, the NASD and the (U.S. Securities and Exchange Commission)." Brokers of securities must be registered with the NASD and in the states where they do business. This combination of self-regulatory and federal regulation "allows for much of the work to be done without government funds with just a smaller amount of funding for government oversight.",

\footnotetext{
${ }^{4}$ Insurance Marketplace Standards Working Group (2004, p. 2).

${ }^{5}$ Insurance Marketplace Standards Working Group (2004, p. 4).

${ }^{6}$ NASD, Working Group (2005).

${ }^{7}$ Insurance Marketplace Standards Working Group (2004, p. 6).
} 
Insurance Marketplace Standards Association (IMSA)

IMSA was created in 1996. IMSA's mission is "to strengthen trust and confidence in the life insurance industry by requiring member companies to demonstrate commitment to high, ethical marketplace standards" in the life insurance, long-term care insurance and annuity products industry.

The IMSA methodology and template were initially developed to provide company managers with a new set of quantitative and qualitative tools to help manage organizations in a way that would keep them compliant with laws and certain agreed upon ethical principles. IMSA is partially predicated on the Total Quality Management concept developed by Dr. W. Edward Deming. Among its many useful dictums is "if you cannot measure it, you cannot manage it." In their search for excellence and continuous improvement, companies must maintain an infrastructure of policies and procedures to collect data, analyze it and take constructive steps based on that data. It is intended to detect and resolve problems early such as questionable marketing, sales and distribution practices.

IMSA qualification is the only credential of quality that a life insurance company can earn in the United States. IMSA standards are codified in the six Principles of Ethical Market Conduct with a supporting set of Codes. To qualify, a life insurer must conduct a thorough internal assessment of its existing policies and procedures to determine whether it complies with IMSA standards. Thereafter, the company must successfully undergo a comprehensive review by a qualified independent assessor (QIA) to ensure that the company has in place an effective system of compliance throughout the organization. By the end of the IMSA review process, a company seeking IMSA qualification must have documented compliance with a minimum of 144 separate criteria.

IMSA qualification does not reflect a company's operations at a single moment in time. Rather, it requires an ongoing commitment of financial and human resources as the company must undergo a new assessment every 3 years that evaluates the company's ongoing compliance with IMSA's standards over the prior 3-year period. IMSA has denied requalification to companies that have failed to maintain the necessary practices and procedures.

Interestingly, the IMSA principles and template correspond to the 10 elements of a "culture of compliance" as previously described. IMSA's requirements of its qualified companies illustrate the key elements of good corporate compliance culture.

A company's culture of ethical behavior should reflect accountability at all levels of an organization. Ethical leadership will produce a company that is driven by customer interests in conjunction with stockholder interest.

Although IMSA focuses primarily on the marketing, advertising, sales and customer service of a company's operations, the compliance infrastructure typically also fosters collaboration between the product development, underwriting, marketing, sales and compliance departments. In such an environment, questions are being asked and answered including "can the promises made with this product be kept?" Even if the answer is "yes," consideration must be given to whether the product may be too complex to be adequately explained to clients. These deliberations at all levels of the company create an atmosphere, where 
establishing and maintaining customer trust is one of the key factors in business decisions.

A fundamental component of the IMSA program is the belief that continuous improvement is essential in an organization. IMSA-qualified companies are constantly self-assessing with the intent of identifying potential problems.

\section{Future integration - restoring trust}

It is not only the financial services industry that has unilaterally caused the deterioration of public confidence. Consequently, it is not the industry's sole responsibility to restore that trust. Companies, working together with regulators, can accomplish a great deal to rebuild the trust that has been damaged and, for some, destroyed.

One way that can happen is to establish a consistent set of standards for appropriate and acceptable marketplace conduct. Insurance regulation should foster a healthy, competitive marketplace and protect consumers. However, the absence of a system of consistent regulatory standards in the United States to fulfill these primary goals makes it impossible for companies to fulfill their potential.

Today in the U.S., the insurance industry is regulated primarily at the state, not the federal, level. A U.S. General Accountability Office study in 2003, "Insurance Regulation: Common Standards and Improved Coordination Needed to Strengthen Market Conduct Regulation," documented the wide variance between the performance of some state insurance regulators and others.

The report is critical of a U.S. system with market conduct oversight criteria and procedures that vary widely among the states. The report reinforces the comparison of state market conduct exams to snowflakes - no two are alike. Despite considerable activity by the many states, there is little coordination, collaboration or consistency among the states. ${ }^{8}$

A nationwide, professional organization such as IMSA offers a consistent, uniform approach for appropriate market conduct. IMSA standards provide a single national template. The broad system of policies and procedures put in place by a company to achieve and maintain IMSA qualification is designed to provide a larger perspective of a company's corporate culture of compliance. An important value of this perspective is the emphasis on, not just identification of specific technical violations, but the detection and correction of market conduct improprieties before they become widespread or systemic.

There are inherent difficulties in attempting to effectuate change in the 50 -state federal system, where each state is governed by laws adopted by its state legislature, managed by a state governor with veto authority and dependent on a staff of bureaucrats to implement laws and regulations. Most meaningful change and improvements to the U.S. insurance regulatory system have come about only after considerable pressure and scrutiny by federal officials in Washington, DC, regarding

\footnotetext{
${ }^{8}$ U.S. Government Accounting Office (2003, p. 3).
} 
particular marketplace or regulatory problems or inadequacies. Recently, the U.S. Congress along with state and federal public policymakers have renewed the debate concerning the benefits and shortcomings of the U.S. regulatory system and the potential for modernization.

There have been many encouraging indications within the past few years that the value of professional organizations is being recognized and, therefore, woven into the future regulatory and marketplace infrastructure. This would be consistent with the past experience of the health-oriented professional organizations, which initially failed to gain acceptance among state insurance regulators in the 1990s. However, the drafting of proposed federal legislation to overhaul the U.S. health care and insurance systems by President Clinton produced a comprehensive document that included recognition of the professional organizations. It was this federal recognition in Washington, DC, that finally prompted the states to acknowledge the valuable role for professional organizations. Since then, URAC and NCQA have been widely accepted and recognized throughout the United States, including specific statutory and regulatory recognition in many states.

Like a dog unwilling to relinquish a bone, the U.S. Congress seems unwilling to abandon its efforts to prompt or force much-needed improvements to the state-based system of insurance regulation. The Financial Services Committee of the U.S. House of Representatives has been working for nearly 2 years on proposed legislation that would retain the state-based system while establishing significant protocols to enhance uniformity and consistency. The proposed State Modernization and Regulatory Transparency Act or SMART Act would recognize the value of ensuring that companies establish and maintain a culture of compliance and an infrastructure designed to maintain and address problems as they arise. In addition, the SMART Act specifically cites the importance of a best practices organization such as IMSA whose central mission is to promote high ethical standards in the marketplace.

It is unclear whether this law will ever be enacted. However, it has served to facilitate the acceptance of organizations such as IMSA, just as proposed federal legislation did a decade earlier for professional organizations focused on health care and insurance. The NAIC and state regulators have finally begun to recognize the true value of IMSA and the benefits to consumers and regulators of having companies committed to doing business the right way - whether a regulator happens to be looking over a company's shoulder on a particular day. If structured correctly, all interests can benefit from substantive professional organizations promoting quality products or services and ethical behaviour in the marketplace.

\section{Finding the balance}

Of course, there are differing perspectives on the marketplace, free enterprise and the role of government. Symptomatic of our times are the recent words of New York Attorney General Spitzer:

The rule that I have come to live by...is that only government, at the end of the day, can indeed enforce rules of integrity and transparency in the marketplace... If we believe the market depends on integrity and fair dealing, 
government must step in to make these cases and make sure that the rules are honoured.

"Self regulation has failed," said Spitzer. ${ }^{9}$

Professional or self-regulatory organizations like IMSA in the U.S. and Raising Standards in Britain, are proving Attorney General Spitzer wrong. It is not a task that can be achieved overnight and it requires dedication and resolve from all players in the industry. But the end result is nothing less than a competitive, free marketplace where consumers are adequately protected and companies thrive because they choose to operate under high standards of honesty and integrity.

\section{References}

Insurance Marketplace Standards Working Group of Life Insurance and Annuities (A) Committee (2004) White paper on Best Practices Organizations, as adopted at the 2004 Summer National Meeting.

NASD (2005) 'About NASD', www.NASD.org accessed April 26, 2005.

Schapiro, M.L. (2005) Remarks by Mary L. Schapiro, NASD President, Regulatory Policy \& Oversight, April 4.

Spitzer, E. (2005) ‘Corporate Responsibility’, National Press Club Newsmakers Luncheon with Eliot Spitzer, Attorney General of New York, January 31.

URAC (2005) 'About URAC', www.URAC.org accessed April 26, 2005.

U.S. Government Accounting Office (September 2003) 'Insurance Regulation: Common Standards and Improved Coordination Needed to Strengthen Market Conduct Regulation', (GAO-03-433), September.

\section{About the Author}

Brian K. Atchinson serves as Executive Director of the Insurance Marketplace Standards Association (IMSA). IMSA is a nonprofit organization promoting high ethical standards in the marketing, sales and service of life insurance, annuities, and long-term care insurance.

A graduate of the University of Massachusetts at Boston, he earned his law degree from Syracuse University College of Law.

\footnotetext{
${ }^{9}$ Spitzer (2005).
} 